\title{
Tempestade solar e seus efeitos na lonosfera. Observação de uma tempestade geomagnética sobre a cidade de Ji-Paraná - Brasil (Outubro 2013) com dados de GPS (NovAtel).
}

\author{
Lenidia Renz; Newton Silva de Lima ; Alan dos Santos Ferreira; Leonaldo de Menezes Moraes; Matheus Elia Hage \\ Rodrigues; Diego Macedo de Almeida; Rodrigo de Souza Machado; Elaine Chrystine da Silva Albuquerque. \\ Centro Universitário Luterano de Manaus - ULBRA \\ Av. Carlos Drummond de Andrade, 1460 (Japiim II - Conj. Atílio Andreazza) \\ CEP 69077-730 Tel. (92) 3616-9800 Manaus Amazonas - Brasil \\ e-mail: diegomacedo07@gmail.com@gmail.com \\ Copyright 2014, SBGf - Sociedade Brasileira de Geofísica
}

Este texto foi preparado para a apresentação no VI Simpósio Brasileiro de Geofísica, Porto Alegre, 14 a 16 de outubro de 2014. Seu conteúdo foi revisado pelo Comitê Técnico do VI SimBGf, mas não necessariamente representa a opinião da SBGf ou de seus associados. É proibida a reprodução total ou parcial deste material para propósitos comerciais sem prévia autorização da SBGf.

\section{Resumo}

No dia 2 de outubro de 2013, ocorreu uma forte tempestade solar que atingiu a escala 7,7 do índice $\mathrm{Kp}$. Em análise do índice Dst para o mesmo dia, houve uma queda na componente (Bz) do campo magnético na ordem de $-80 \mathrm{nT}$. Dois dias depois, entre os dias 4 e 5 de outubro, ocorrendo variações do índice TEC. O vento solar demorou dois dias para chegar à Terra nestas condições. Tendo em vista que tanto o índice Kp quanto o Dst indicaram uma forte tempestade geomagnética, conclui-se que as perturbações do índice TEC dos dias 4 e 5 de outubro foram causadas por um Dst que atingiu a Terra e carregou a ionosfera de íons e elétrons interferindo nas comunicações via satélite.

\section{Introdução}

O Sol não é uma estrela de comportamento estável. A cada 11 anos, seu campo magnético se inverte, resultando em períodos de intensa atividade (máximo solar) e períodos de relativa calmaria (mínimo solar). Durante o máximo solar, ocorrem muitas explosões solares por dia. Esses fenômenos, também conhecidos como "solar flare" (Fig. 2), são liberações súbitas de grande quantidade de energia, da ordem de 100 megatons, aquecendo a cromosfera solar a temperaturas que chegam a 30 milhões de Kelvin. Por vezes, a energia da explosão é tão intensa que há uma liberação de massa coronal (bolhas de matéria formada por prótons, elétrons e íons) para o meio interplanetário, fenômeno chamado de vento solar (Silva, 2006).

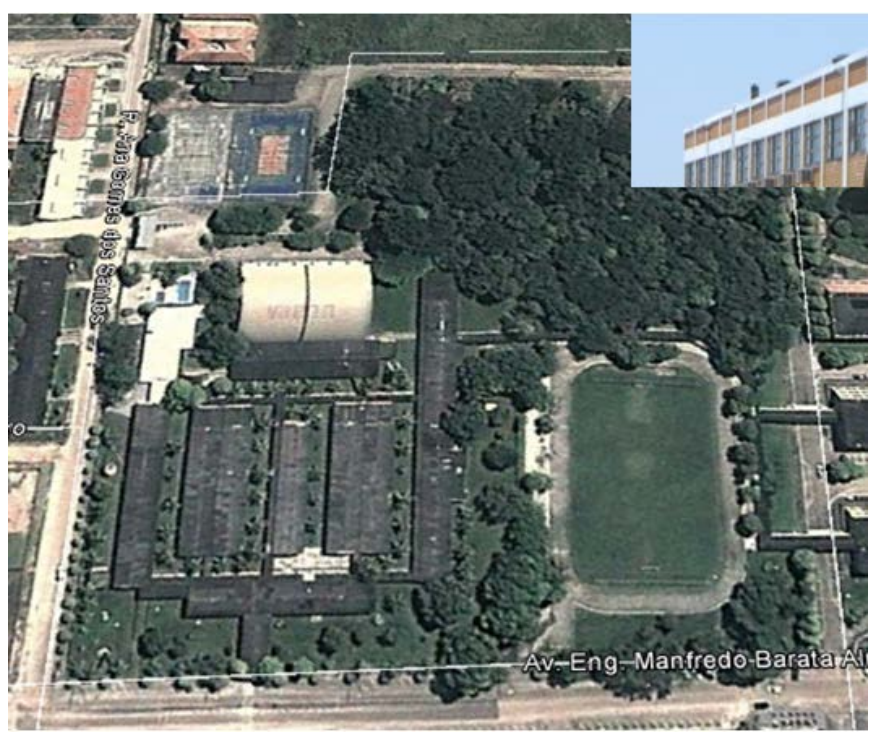

Fig. 1: ULBRA de Ji-Paraná. (GPS (105ำ e $\left.61^{\circ} 57^{\prime} O\right)$.

A Terra possui um núcleo de material ferromagnético que responsável por um campo magnético que protege o planeta das tempestades solares, esse campo é conhecido como magnetosfera. Se uma Dst (Fig. 2) se conectar a magnetosfera, pode prejudicar 0 funcionamento de sistemas de satélites, inclusive confundir sistemas de navegação, interromper comunicações de longa distância e causar danos a equipamentos elétricos e eletrônicos (Silva, 2006). 
Tempestades solares e seus efeitos na Ionosfera. Observação de uma Dst sobre a cidade de Ji-Paraná (Out 2013)

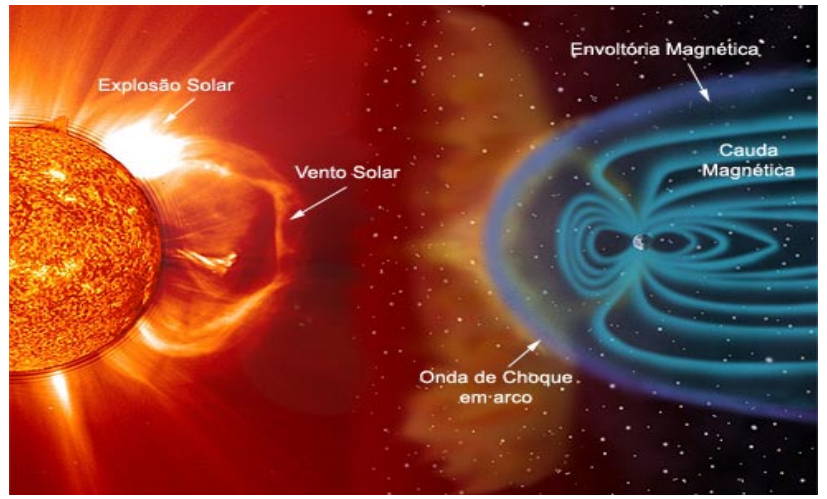

Fig. 2: Interação Sol-Terra

(http://dinamicadaevolucao.blogspot.com.br/2012/02/magnetosfer a.html)

\section{Resultados}

No dia 2 de outubro de 2013, ocorreu uma forte tempestade geomagnética que atingiu a escala 7,7 do índice Kp (Fig. 3). Em análise do índice Dst que nesse mesmo dia, houve uma queda na componente (Bz) do campo magnético na ordem de $-80 \mathrm{nT}$ (Fig.4). Dois dias depois, entre os dias 4 e 5 de outubro, houve degradação do sinal GPS (Fig. 5), adquirido pela estação Ulbra JiParaná (Fig. 1). O vento solar demorou dois dias para chegar na região de choque da magnetosfera terrestre. Mostrados com clareza nos índices Kp e Dst para os dias 4 e 5 de outubro conforme (Figs. 3 e 4). Confirmado pelo índice TEC (Fig. 5). A tempestade geomagnética que atingiu a magnetosfera e conectou-se a ela carregou a ionosfera de íons e elétrons produzindo auroras (boreal e austral) por efeito Compton, nestes dias.

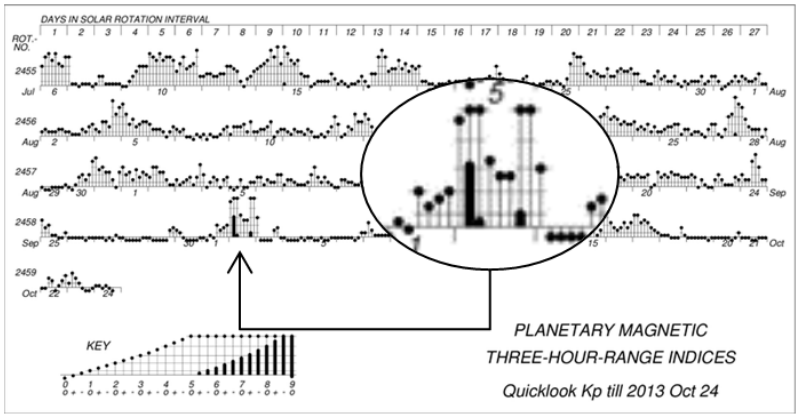

Fig. 3: O índice Kp em 2 de outubro de 2013.

(http://www-app3.gfz-potsdam.de/kp_index/definitive.html)

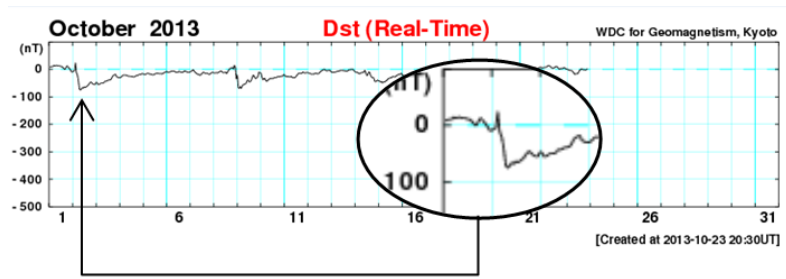

Fig. 4: Índice Dst em 02 Outubro de 2013.

(http://wdc.kugi.kyoto-u.ac.jp/dst_realtime/201310/index.html)

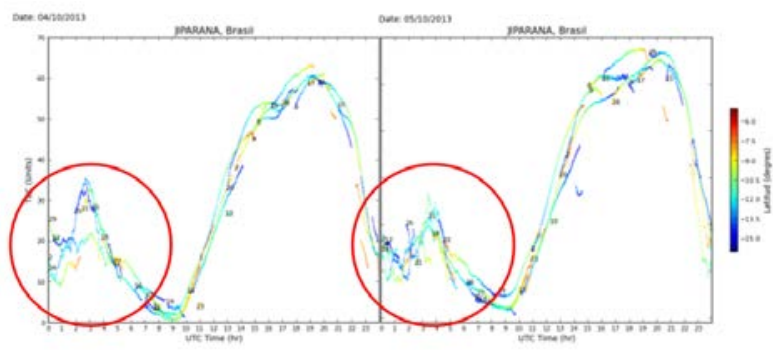

Fig. 5: Os índices TEC do dia 4 e 5 de outubro Fonte: ULBRA de Ji-Paraná, Rondônia/Brasil .

\section{Discussão e Conclusões}

Em tempos de máximo solar (2013), estes monitoramentos da atividade solar, através dos índices (Kp, Dst e TEC) são de fundamental importância para prevenção de sinistros por indução eletromagnética a partir dos polos terrestre e, por conseguinte nos anéis de Van Allen . Permitindo alerta de proteção aos sistemas de satélites, sistemas de navegação, os meios de comunicações e equipamentos elétricos e eletrônicos, fundamentais para a sociedade contemporânea.

\section{Agradecimentos}

Agradecemos nesse trabalho ao apoio dos professores orientadores: Newton Silva de Lima e Alan Ferreira dos Santos; À ULBRA Manaus e Ji-Paraná pelos dados de TEC. A Fundação de Amparo à Pesquisa do Estado do Amazonas; À UNIVAP; LISN e Estação WDC de Kyoto no Japão.

\section{Referências}

- SILVA, Adriana Válio Roque. Nossa Estrela: O Sol. Ed. 1. São Paulo: Livraria da Física, 2006. 
